\title{
EQUIPAMENTOS ALTERNATIVOS PARA 0 ENSINO DE QUÍMICA PARA ALUNOS COM DEFICIÊNCIA VISUAL
}

\author{
ALTERNATIVE EQUIPMENT FOR THE \\ TEACHING OF CHEMISTRY FOR STUDENTS \\ WITH VISUAL IMPAIRMENT \\ Adeilton Pereira Maciel' ${ }^{1}$ Antonio Batista Filho', \\ Gilza Maria Piedade Prazeres ${ }^{1}$
}

\section{RESUMO}

Neste trabalho reportamos uma experiência didáticopedagógica realizada numa turma de Instrumentação para o Ensino de Química do curso de licenciatura em Química da Universidade Federal do Maranhão. Como trabalho de conclusão da disciplina, os discentes deveriam propor e construir equipamentos de pequeno porte para serem utilizados no auxílio ao ensino de Química para alunos com deficiência visual. A turma era composta por oito alunos, que apresentaram os equipamentos que desenvolveram. Um dos discentes destacou-se na execução da atividade, produzindo a balança de um prato e um medidor de volume de líquidos, os quais podem ser utilizados facilmente por alunos com deficiência visual. Aqui mostramos como os equipamentos foram feitos e como podem ser utilizados, seguindo um roteiro experimental proposto pelo aluno de licenciatura em Química. 
Palavras-chave: Materiais alternativos. Ensino de Química. Educação inclusiva.

\section{INTRODUÇÃO}

O ensino de Química no Brasil apresenta muitas dificuldades relacionadas aos procedimentos didático-pedagógicos, e elas pouco contribuem para a efetivação da aprendizagem dessa ciência tão importante para o mundo contemporâneo. Enfocando particularmente o ensino de Química para alunos com deficiência visual, verifica-se que os problemas acentuamse: muitos docentes não possuem formação adequada para lidar com a situação, a metodologia normalmente utilizada é baseada na percepção visual, faltam professores assistentes para acompanhar os alunos com deficiências, poucos são os materiais didáticos e instrumentos disponíveis (FIELD'S et al., 2012; NEPOMUCENO; ZANDER, 2015). Desse modo, o ensino de Química ocorre, muitas vezes, de forma paliativa e quase exclusivamente teórica.

As aulas práticas de Química em si não resolvem os problemas de aprendizagem dessa ciência. É necessário que os conhecimentos prévios dos alunos sejam considerados. Segundo Guimarães (2009),

a mera inserção dos adolescentes em atividades práticas não é fonte de motivação. É necessário que haja o confronto com problemas, a reflexão em torno de ideias inconsistentes por eles apresentadas. Para isso, deve levar-se em consideração os modelos alternativos por eles demonstrados e compará-los aos aceitos cientificamente (GUIMARÃES, 2009, p. 202). 
A preocupação com o ensino experimental para alunos com deficiência física não é novidade. Desde o final da década de 1970, vários equipamentos de pequeno porte têm sido desenvolvidos com o objetivo de facilitar o ensino de ciências para alunos com deficiências visuais. Dentre esses, destaca-se o trabalho de Malone e Lucchi (1981), que apresentou objetos comuns adaptados para serem utilizados como instrumentos de medidas de volumes. Em 2001, Miner e coautores publicaram o livro Teaching Chemistry to students with disabilities: a manual for high schools, colleges, and graduate programs, no qual mostraram como trabalhar atividades práticas de Química com alunos que apresentam deficiência visual e evidenciaram a necessidade de um ambiente e materiais adaptados para que o discente desenvolva atividades experimentais.

O governo brasileiro tem desenvolvido ações no sentido de capacitar professores para atenderem às necessidades de alunos com deficiência visual, bem como tem apresentado vários equipamentos adaptados e com o objetivo de facilitar a inclusão desses estudantes no sistema de ensino regular (SÁ; CAMPOS; SILVA, 2007). Poucos desses equipamentos estão voltados para as aulas práticas de Química.

Nesse contexto, o principal objetivo deste trabalho é mostrar que é possível introduzir, no currículo de um curso de licenciatura em Química, atividades relativas à inclusão de alunos com deficiência visual e quebrar paradigmas ligados ao ensino de ciências para alunos com deficiências visuais, além de estimular a criatividade dos futuros professores para o desenvolvimento de recursos didáticos com materiais alternativos. 


\section{FORMAÇÃO DE PROFESSORES DE QUÍMICA}

$\mathrm{Na}$ sociedade brasileira, geralmente é dito que a educação é a "salvação da nação" e o professor, o responsável pela transformação do mundo. Entretanto, a educação e o professor ainda não são prioritários a ponto de serem fornecidas condições para o desenvolvimento adequado do processo educativo, bem como para que a missão do professor seja valorizada (GATTI; BARRETO, 2009). A principal razão da diferença entre o discurso e a realidade é que a educação é um processo que depende de vários atores, mas é o professor que tem um papel central.

A formação adequada do professor é fundamental para o bom desenvolvimento das atividades didático-pedagógicas que ele realiza e deve se processar de tal forma que o instrumentalize para enfrentar com dinamicidade, iniciativa e criatividade os problemas que se apresentam no cotidiano da profissão. Desse modo, é importante que as turmas de formação pedagógica não sejam compostas por alunos de cursos diferentes, visto que eles apresentam necessidades distintas e que, como profissionais, desenvolverão atividades específicas.

Gauche e colaboradores (2008) destacaram como um curso de licenciatura em Química tem buscado assumir a identidade como formador de professores, desvinculando-se do curso de bacharelado e reformulando os conteúdos curriculares. A maioria dos cursos de licenciatura em Química no Brasil tem adotado estratégia semelhante. No entanto, quando se refere à inclusão de alunos portadores de algum tipo de deficiência, os currículos dos cursos de Química Licenciatura ainda 
oferecem poucos subsídios para que os futuros professores possam atuar de forma efetiva.

Durante os cursos de graduação, atividades didáticas relacionadas com inclusão de alunos portadores de deficiência são, geralmente, iniciativas isoladas de alguns professores. No processo de formação dos professores, é necessário que essas iniciativas sejam convertidas em atividades curriculares, dado que a inclusão de alunos com necessidades especiais tem acontecido numa dinâmica maior que a adaptação dos currículos para formação de professores na área de Química.

\section{USO DE MATERIAIS ALTERNATIVOS PARA O ENSINO DE QUÍMICA}

A falta de experimentação em Química na educação básica é um problema que atinge a grande maioria das escolas públicas e boa parte das particulares no Brasil. Os motivos para essa carência são os mais variados; porém, pode ser destacada a falta de laboratórios, reagentes, vidrarias, acessórios específicos para laboratório e tempo disponível na carga horária da disciplina (PONTES et al., 2008).

No final da década de 1980, Chrispino (1989) mostrou que é possível fazer Química Experimental utilizando-se materiais alternativos. No trabalho que esse autor apresentou, foram expostos experimentos de Química nos quais foram utilizados materiais de fácil aquisição e baixo custo, encontrados em casa, em sucatas e/ou no comércio tradicional. 
O uso de materiais alternativos na experimentação de Química não deve ser visto apenas como uma maneira de substituir reagentes, vidrarias e acessórios específicos para laboratório, mas também como uma forma de reutilizar materiais que são potenciais poluidores. Desse modo, temos dois enfoques: um técnico e outro ambiental. Porém, Maciel e Lima (2011) alertam que

$$
\begin{aligned}
& \text { o professor menos experiente com o uso de } \\
& \text { materiais alternativos deve fazer inicialmente } \\
& \text { apenas pequenas adaptações no que diz respeito } \\
& \text { à substituição de material de laboratório, sempre } \\
& \text { prezando a segurança dos participantes (MACIEL; } \\
& \text { LIMA, 2011, p. 61). }
\end{aligned}
$$

No curso de licenciatura em Química da Universidade Federal do Maranhão, o uso de materiais alternativos para o ensino de Química é parte das atividades desenvolvidas na disciplina Instrumentação para o Ensino de Química. Nessa disciplina, os alunos de licenciatura têm um contato mais íntimo com o planejamento de atividades experimentais em Química e com a adaptação delas para a utilização de materiais alternativos.

Os professores da disciplina buscam incentivar a criatividade dos alunos de graduação, propondo atividades desafiadoras e que ainda não foram trabalhadas durante o curso. Uma dessas atividades é o desenvolvimento de materiais específicos para se ensinar Química a alunos com deficiência visual.

No início da disciplina, é perceptível o semblante preocupado de alunos que ainda não haviam sido colocados na posição de autor ou criador de algo desafiador. Com o decorrer das atividades, os discentes perceberam que são capazes de 
superar os desafios. Então, passaram a desenvolver os próprios projetos e a pôr em prática novas ideias. Algumas delas são muito criativas, interessantes e potencialmente aproveitáveis para a prática pedagógica.

\section{METODOLOGIA PARA ELABORAÇÃO E USO DOS EQUIPAMENTOS}

A disciplina Instrumentação para o Ensino de Química é parte dos componentes curriculares pedagógicos do curso de Química Licenciatura da Universidade Federal do Maranhão. 0 objetivo da disciplina é proporcionar conhecimentos teóricos e práticos que possibilitem aos futuros professores uma visão crítica do processo de ensino/aprendizagem relacionado ao conteúdo do ensino médio e efetivar o domínio de técnicas e métodos de ensino face às situações didáticas. O conteúdo da disciplina envolve: planejamento, elaboração e execução de atividades laboratoriais relacionadas ao conteúdo do ensino médio; montagem de equipamentos alternativos de laboratório; literatura especializada para o ensino da Química. A carga horária é de noventa horas/aula, dividida em dois encontros semanais com três aulas cada um.

A proposta de desenvolvimento de projetos de criação e uso de equipamentos para serem utilizados por alunos da educação básica com deficiência visual foi apresentada aos discentes da disciplina Instrumentação para o Ensino de Química no início do primeiro semestre letivo de 2015 , de modo a permitir que dispusessem de tempo suficiente para a conclusão da tarefa. Todo o conteúdo da disciplina foi direcionado para que os alunos tivessem condições de construir equipamentos 
para experimentação que pudessem ser utilizados por estudantes com deficiência visual, utilizando-se materiais não convencionais e de baixo custo.

No início da disciplina, para favorecer a fundamentação teórica dos projetos, foi trabalhado o tópico "Literatura especializada para o ensino da Química". Nessa parte, foram apresentados os caminhos que devem ser seguidos para que sejam obtidas informações sobre os diversos assuntos relacionados com Química: bases de dados digitais, periódicos, livros, boletins e sites. Em seguida, foram operacionalizadas buscas sobre o tema.

Na sequência, foi apresentada a parte didático-pedagógica da disciplina, na qual os alunos tomam contato com as técnicas necessárias para a realização de um bom planejamento de atividade, seguida da execução e da avaliação desse planejamento.

A execução das atividades consistiu em buscar experimentos tradicionais e novos na literatura científica e em adaptálos para a execução com materiais alternativos. Após o domínio desses procedimentos, seguiu-se à adaptação para o uso por alunos com deficiência visual. Foram priorizados os experimentos mais simples, e depois a atenção voltou-se para propostas mais elaboradas.

Os trabalhos foram desenvolvidos em laboratório de aulas didáticas, sob a orientação e o acompanhamento do professor responsável pela disciplina. Todos os alunos frequentadores da turma desenvolveram um projeto que levou à construção de pelo menos um equipamento. No desenvolvimento do projeto, 
cada um dos discentes participou de etapas que envolviam uso de ferramentas de corte (tesouras), de força (martelos, alicates), de solda (ferro de soldar) e instrumentos específicos de laboratório. No início do projeto, alguns discentes apresentaram dificuldades no manuseio de ferramentas, mas, em pouco tempo, tornaram-se hábeis para utilizá-las com praticidade e segurança.

No final da disciplina, cada um dos discentes apresentou o projeto completo, o que envolveu a apresentação dos equipamentos construídos e dos planos de aulas experimentais, incluindo um roteiro para execução de experimento que utiliza o equipamento proposto.

Dentre os projetos propostos e executados pelos discentes da disciplina Instrumentação para o Ensino de Química, no primeiro semestre letivo de 2015, destacam-se dois equipamentos - uma balança e um medidor de volumes que podem ser utilizados por alunos com deficiência visual.

\section{CONSTRUÇÃO E USO DE BALANÇA E MEDIDOR DE VOLUMES}

Todos os materiais utilizados para construção da balança e do medidor de volumes adaptados para estudantes de ensino médio com deficiência visual são alternativos e de fácil aquisição em comércio, marcenarias, serralherias, oficinas ou sucatas. Esses materiais também podem ser facilmente encontrados nas residências, sem que seja necessária a compra. 
No Quadro 1, estão listados os principais materiais empregados para construção dos equipamentos e os locais onde podem ser encontrados. Além desses, também foram utilizados chave de fenda, alicate, furadeira e brocas, serra ou serrote para madeira, serra para aço, régua, adesivo epóxi, lixa e marcador permanente.

Quadro 1 - Materiais para construção dos equipamentos

\begin{tabular}{|c|c|c|c|}
\hline \multicolumn{4}{|c|}{ BALANÇA } \\
\hline Material & Descrição & Quantidade & $\begin{array}{c}\text { Onde } \\
\text { encontrar }\end{array}$ \\
\hline \multirow{3}{*}{$\begin{array}{l}\text { Pedaços de } \\
\text { madeira }\end{array}$} & $20 \mathrm{~cm} \times 8 \mathrm{~cm}$ & 1 & \multirow{3}{*}{$\begin{array}{c}\text { Marcenaria, } \\
\text { construções } \\
\text { ou } \\
\text { residência }\end{array}$} \\
\hline & $\begin{array}{c}8 \mathrm{~cm} \times 2 \mathrm{~cm} \times \\
2 \mathrm{~cm}\end{array}$ & 2 & \\
\hline & $\begin{array}{c}20 \mathrm{~cm} \times 2 \mathrm{~cm} \times \\
2 \mathrm{~cm}\end{array}$ & 1 & \\
\hline \multirow{2}{*}{$\begin{array}{c}\text { Parafusos } \\
\text { para madeira, } \\
\text { cabeça chata, } \\
\text { fenda simples }\end{array}$} & $3,5 \mathrm{~mm} \times 30 \mathrm{~mm}$ & 4 & \multirow{3}{*}{$\begin{array}{c}\text { Comércio or } \\
\text { sucata }\end{array}$} \\
\hline & $2,5 \mathrm{~mm} \times 8 \mathrm{~mm}$ & 2 & \\
\hline $\begin{array}{l}\text { Pino com } \\
\text { rosca externa } \\
\text { em uma das } \\
\text { extremidades }\end{array}$ & $4,2 \mathrm{~mm} \times 50 \mathrm{~mm}$ & 1 & \\
\hline $\begin{array}{c}\text { Elo de } \\
\text { corrente de } \\
\text { bicicleta }\end{array}$ & Parte fêmea & 2 & $\begin{array}{c}\text { Oficina de } \\
\text { bicicletas ou } \\
\text { sucata }\end{array}$ \\
\hline Copo acrílico & $50 \mathrm{~mL}$ & 1 & \multirow{2}{*}{$\begin{array}{l}\text { Residência } \\
\text { ou comércio }\end{array}$} \\
\hline $\begin{array}{c}\text { Embalagem } \\
\text { PEAD }^{i}\end{array}$ & $50 \mathrm{~mL}$ & 1 & \\
\hline
\end{tabular}

(continua) 


\begin{tabular}{|c|c|c|c|}
\hline Material & Descrição & Quantidade & $\begin{array}{c}\text { Onde } \\
\text { encontrar }\end{array}$ \\
\hline $\begin{array}{c}\text { Arame de aço } \\
\text { ou cobre }\end{array}$ & $3 \mathrm{~mm} \times 250 \mathrm{~mm}$ & 1 & $\begin{array}{l}\text { Comércio, } \\
\text { sucata ou } \\
\text { residência }\end{array}$ \\
\hline $\begin{array}{l}\text { Arruelas de } \\
\text { metal lisas, } \\
\text { sem chanfro }\end{array}$ & $\begin{array}{l}\text { Furo }>4,2 \mathrm{~mm} \\
\text { Massas variando } \\
\text { entre } 0,5 \text { e } 20 \\
\text { gramas }\end{array}$ & Várias & $\begin{array}{l}\text { Comércio ou } \\
\text { sucata }\end{array}$ \\
\hline $\begin{array}{l}\text { Arruela } \\
\text { retangular }\end{array}$ & $2 \mathrm{~cm} \times 4 \mathrm{~cm}$ & 1 & Sucata \\
\hline \multicolumn{4}{|c|}{ MEDIDOR DE VOLUMES } \\
\hline Material & Descrição & Quantidade & $\begin{array}{c}\text { Onde } \\
\text { encontrar }\end{array}$ \\
\hline Seringa PP ii & $20 \mathrm{~mL}$ & 1 & \\
\hline $\begin{array}{c}\text { Pedaço de } \\
\text { PVC }^{\text {iii ou PS }}\end{array}$ & $\begin{array}{c}\text { Placa } 3 \mathrm{~cm} \mathrm{x} \\
3 \mathrm{~cm} \\
\text { Espessura }>2 \\
\mathrm{~mm}\end{array}$ & 1 & $\begin{array}{c}\text { Residência ou } \\
\text { comércio }\end{array}$ \\
\hline
\end{tabular}

Legenda: 'PEAD: polietileno de alta densidade; "PP: polipropileno, iiiPVC: policloreto de vinila; ivPS: poliestireno.

Fonte: elaborado pelos autores, 2016.

\section{Construção da balança adaptada}

As peças que compõem a balança estão apresentadas na Figura 1. Os pedaços de madeira necessários para a montagem foram coletados na residência de um dos autores deste trabalho e serrados com o auxílio de serra ou serrote nas dimensões 
indicadas no Quadro 1, mas também podem ser adquiridos em uma marcenaria.

Figura 1 - Peças para construção da balança

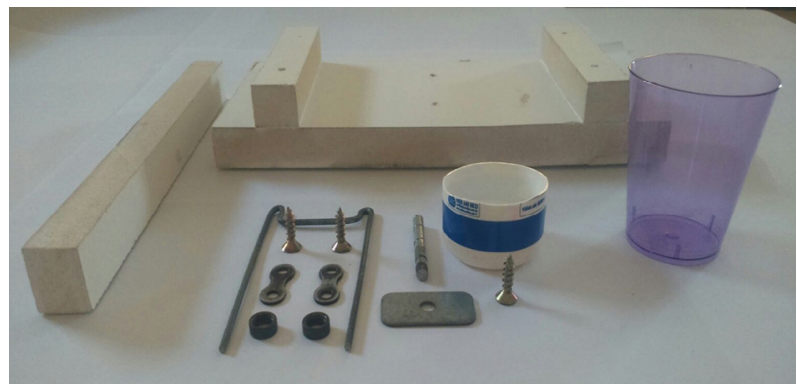

Fonte: arquivo dos autores.

A base da balança foi construída com a tábua de $20 \mathrm{~cm} \times 8$ $\mathrm{cm}$, em cujas extremidades foram parafusados os dois pedaços de madeira $8 \mathrm{~cm} \times 2 \mathrm{~cm} \times 2 \mathrm{~cm}$, que servirão como batedores e pontos de referência para medida do nível do travessão da balança. No centro da base, foram feitos dois furos para encaixar a haste de metal que sustenta o travessão.

A haste da balança foi montada com o arame metálico dobrado em forma de $U$, com $50 \mathrm{~mm}$ na parte central e $100 \mathrm{~mm}$ nas duas laterais. A parte central do $U$ foi curvada para permitir o encaixe de dois elos de corrente de bicicleta, um em cada uma das laterais.

O travessão da balança foi construído com o pedaço de madeira $20 \mathrm{~cm} \times 2 \mathrm{~cm} \times 2 \mathrm{~cm}$ e foi adaptado à haste por meio dos elos de corrente de bicicleta, com o auxílio de parafusos. 
Um recipiente de polipropileno (embalagem plástica usada) foi coletado na residência de um dos autores e cortado a cerca de $3 \mathrm{~cm}$ a partir do fundo e fixado a uma das extremidades do travessão com adesivo epóxi. Esse recipiente foi utilizado como suporte para o copo de acrílico no qual foram adicionados os sólidos que foram pesados. Na outra extremidade do travessão, fixou-se a arruela retangular e o pino rosqueado diretamente na madeira. As massas dos materiais fixados nas duas extremidades devem ser equivalentes, de tal forma que o travessão, ao ser posicionado na haste, fique nivelado. A haste de metal foi encaixada nos dois furos da base de madeira e fixada com adesivo epóxi ou similar.

Após montagem, as partes da balança foram lixadas para se removerem farpas, pontas e imperfeições que pudessem causar cortes acidentais nos usuários com deficiência visual. A Figura 2 apresenta uma imagem da balança montada e pronta para fazer medidas de massas de diversos sólidos, tais como grãos, blocos, grumos ou pós.

As massas das arruelas foram determinadas em uma balança analítica e foram utilizadas como pesos. 
Figura 2 - Balança a ser utilizada por alunos com deficiência visual

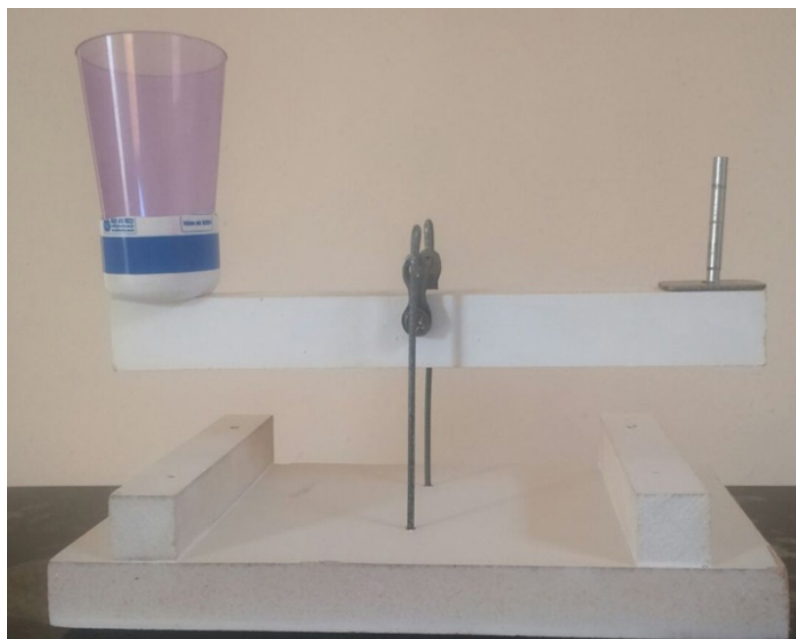

Fonte: arquivo dos autores.

\section{Construção do medidor de volume}

Para se construir o medidor de volume, foram feitas gradações com marcador permanente no êmbolo da seringa, correspondentes a cada volume que será medido. Com uma serra fina (utilizada para cortar aço), foram feitas fendas de cerca de $5 \mathrm{~mm}$ em três dos quatro lados do êmbolo. Essas fendas foram utilizadas para se encaixar uma trava que tem a função de fixar o volume a ser medido. 
A trava foi confeccionada com uma pequena placa de plástico rígido na qual foram feitos cortes que permitiram o encaixe no êmbolo nas fendas do êmbolo (FIGURA 3).

Figura 3 - Medidor de volume a ser utilizado por alunos com deficiência visual

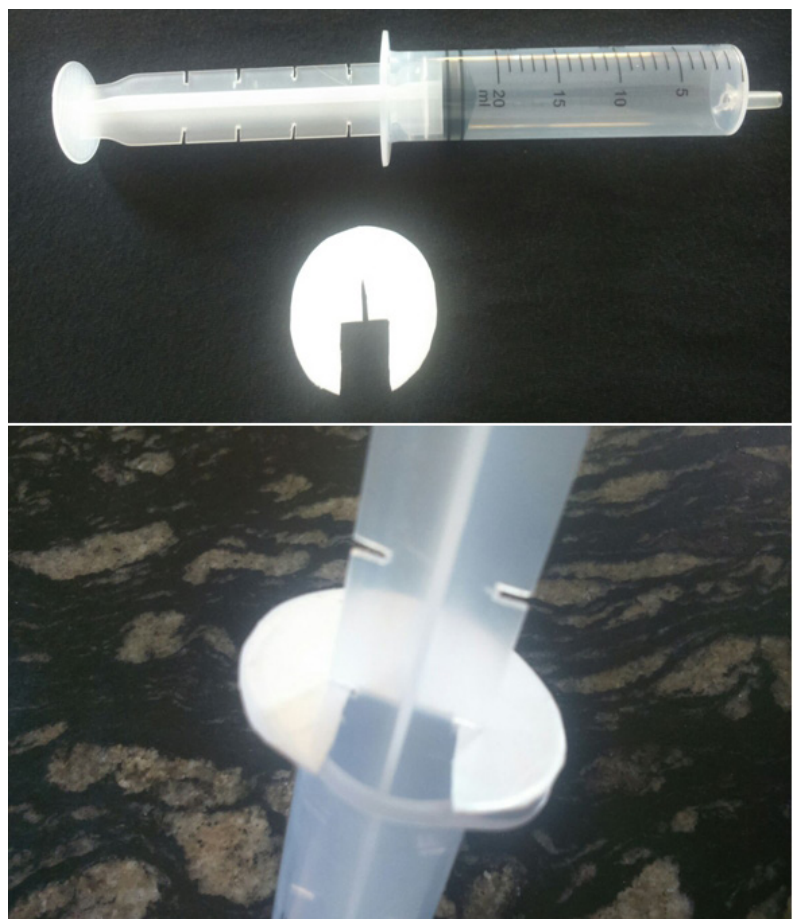

Fonte: arquivo dos autores. 


\section{PROCEDIMENTOS DE PESAGEM EM BALANÇA ADAPTADA}

Nesta parte do trabalho, será mostrado como os alunos com deficiência visual poderão utilizar a balança construída. Porém, esses procedimentos ainda não foram testados com o públicoalvo. Os testes foram realizados com os alunos da disciplina com os olhos vendados.

\section{Pesagem de massa desconhecida}

Colocar a amostra a ser pesada no recipiente da balança (copo de acrílico). Em seguida, encaixar aos poucos os pesos prédefinidos (arruelas) no pino que está na outra extremidade do travessão. Posicionar as pontas dos dedos no batedor da balança para sentir o movimento do braço e verificar se a posição de equilíbrio foi atingida. Caso o último peso adicionado tenha provocado ultrapassagem do ponto de equilíbrio, esse deve ser retirado e substituído por um peso menor. Essa etapa deve ser repetida até se chegar ao ponto de equilíbrio.

\section{Pesagem de massa conhecida}

Colocar no pino da balança os pesos referentes à massa da amostra a ser pesada. Em seguida, adicionar aos poucos a amostra e, com as pontas dos dedos, sentir o movimento do travessão e a posição de equilíbrio. Caso o ponto de equilíbrio seja ultrapassado, deve ser retirada uma pequena quantidade da amostra e deve-se voltar a adicioná-la aos poucos, até 
chegar à pesagem correta. Caso seja necessário, este último passo pode ser repetido.

\section{PROCEDIMENTOS PARA O USO DO MEDIDOR DE VOLUME ADAPTADO}

Transferir uma porção do líquido que será medido para um recipiente adequado. Introduzir o medidor no recipiente até tocar o fundo. Encher o medidor completamente. Em seguida, colocar a trava na medida desejada e devolver o excedente do líquido para o recipiente. Recolher o volume desejado.

Esse tipo de medidor de volumes não se aplica a medições de volumes desconhecidos de líquidos, mas pode ser usado para se medir volumes previamente determinados. Essas medidas são utilizadas para preparação ou diluição de soluções, que são procedimentos corriqueiros nos laboratórios de Química.

Observou-se que os erros relativos máximos para as medidas utilizando-se esses equipamentos ficaram abaixo de 10\%, quando comparados aos equipamentos comercias utilizados no laboratório por alunos sem deficiências visuais. Porém, os desvios observados entre os valores medidos com a balança adaptada ficaram abaixo de $5 \%$ e, entre os volumes medidos com o medidor de volume, foram menores que $1 \%$. Esses resultados mostram que os equipamentos possuem exatidão razoável e ótima precisão nas medições. 


\section{SUGESTÃO DE ROTEIRO EXPERIMENTAL}

Tema: preparo de soluções

Objetivo: preparar uma solução utilizando-se equipamentos adaptados para alunos com deficiência visual.

\section{Materiais utilizados:}

- balança adaptada;

- $\quad$ medidor de volume adaptado;

- $\quad$ becker de PEAD $200 \mathrm{~mL}$;

- $\quad$ bastão de vidro;

- $\quad$ pisseta.

\section{Reagentes:}

- $\quad$ água destilada;

- cloreto de sódio.

\section{Procedimentos}

Pesagem em balança adaptada

Coloque na haste da balança os pesos referentes à amostra a ser pesada. Em seguida, adicione aos poucos a amostra, verificando, com as pontas dos dedos no batedor da balança, para sentir o movimento de equilíbrio. No caso de se ultrapassar o ponto de equilíbrio, retire um pouco da amostra e volte a adicioná-la aos poucos até chegar à pesagem correta. Se precisar, repita esse passo. 
Medida de volume em equipamento adaptado (seringa de $20 \mathrm{~mL}$ )

Encha a seringa totalmente. Em seguida, coloque a trava no volume desejado no êmbolo e, em seguida, esvazie-o até tocar na trava. Retire a trava e recolha o volume escolhido em recipiente adequado. Se precisar completar, repita novamente esse procedimento até concluir o volume desejado.

Preparo de $100 \mathrm{~mL}$ de uma solução de $\mathrm{NaCl}$ 0,85M

Pesar $5 \mathrm{~g}$ de $\mathrm{NaCl}$ (balança adaptada), transferir para um becker de $200 \mathrm{~mL}$ e adicionar $60 \mathrm{~mL}$ de água destilada, agite, utilizando um bastão de vidro. Em seguida, adicione mais 40 $\mathrm{mL}$ de água destilada e agite até observar que foi dissolvido todo o cloreto de sódio.

\section{CONSIDERAÇÕES FINAIS}

Comumente não há espaço disponível para alunos com deficiência visual desenvolverem atividades experimentais em Química. Buscando diminuir os obstáculos encontrados com relação à disponibilidade de equipamentos adaptados para deficientes visuais, foram construídos dois equipamentos essenciais para o trabalho laboratorial: uma balança e um medidor de volumes. Os equipamentos foram planejados e construídos por um estudante do curso de Química Licenciatura como parte das atividades de uma disciplina do ciclo profissional. 
Na confeç̧ão dos equipamentos, foram utilizados materiais alternativos, simples, de baixo custo e fáceis de serem coletados ou adquiridos. A disponibilidade de equipamentos adaptados e de baixo custo possibilita que docentes apliquem metodologias de ensino inclusivas, bem como permite que alunos com deficiências visuais sejam sujeitos ativos de aulas experimentais, as quais comprovadamente são essenciais para a eficiência do processo ensino/aprendizagem de Química.

A construção dos equipamentos também mostrou que é possível inserir uma metodologia inclusiva em um currículo tradicional de formação de professores, com destacados resultados didático-pedagógicos e técnicos.

\section{REFERÊNCIAS}

CHRISPINO, A. Ensinando Química experimental com metodologia alternativa. Química Nova, v. 12, n. 2, p. 187-191, 1989.

FIELD'S, K. A. P.; CAVALCANTE, K. L.; MORAIS, W. C. S.; BENITE, C. R. M.; BENITE, A. M. C. Ensino de Química para deficientes visuais: sobre intervenção pedagógica em instituição de apoio. In: ENCONTRO NACIONAL DE ENSINO DE QUÍMICA, 16, 2012, Salvador, [Anais...]. Disponível em: <http://www.eneq2012.qui.ufba.br/ modulos/ submissao/Upload/42492.pdf>. Acesso em: 25 jul. 2016.

GATTI, B. A.; BARRETO, E. S. S. (Coord.). Professores do Brasil: impasses e desafios. Brasília: UNESCO, 2009.

GAUCHE, R.; SILVA, R. R.; BAPTISTA, J. A.; SANTOS, W. L. P.; MÓL, G. S.; MACHADO, P. F. L. Formação de professores 
de Química: concepções e proposições. Química Nova na Escola, n. 27, p. 26-29, 2008.

GUIMARÃES, C. C. Experimentação no ensino de Química: caminhos e descaminhos rumo à aprendizagem significativa. Química Nova na Escola, v. 31, n. 3, p. 198202, 2009.

MACIEL, A. P.; LIMA, J. B. Alternativas para o ensino de química na educação básica: a experiência no cotidiano da docência em química. São Luís: EDUFMA, 2011.

MALONE, L.; LUCCHI, L. Multisensory science education: meeting special challenges. In: CORRICK, B. (Org.). Teaching handicapped student's science. Washington: NEA, 1981.

MINER, D. L.; NIEMAN, R.; SWANSON, A. E. B.; WOODS, M. Teaching Chemistry to students with disabilities: a manual for high schools, colleges, and graduate programs. $4^{\text {th }}$ Edition. American Chemical Society, Washington, D.C., 2001.

NEPOMUCENO, T. A. R.; ZANDER, L. D. Uma análise dos recursos didáticos táteis adaptados ao ensino de ciências a alunos com deficiência visual inseridos no ensino fundamental. Revista do Instituto Benjamin Constant, Rio de Janeiro, v. 1, n. 58, p. 49-63, 2015.

PONTES, A. N.; SERRÃO, C. R. G.; de FREITAS, C. K. A.; dos SANTOS, D. C. P.; BATALHA, S. S. A. O ensino de Química no nível médio: um olhar a respeito da motivação. In: ENCONTRO NACIONAL DE ENSINO DE QUÍMICA, 14, 2008, Curitiba [Anais...]. Disponível em: <http://www. quimica.ufpr.br/eduquim/eneq2008/resumos/R0428-1. pdf>. Acesso em: 25 jul. 2016. 
SÁ, E. D.; CAMPOS, I. M.; SILVA, M. B. C.; Atendimento educacional especializado em deficiência visual. Brasília: MEC; SEESP, 2007.

\section{ABSTRACT}

In this work, we report a didactic-pedagogical experiment conducted in a class of Instrumentation for Teaching of Chemistry from the Chemistry teaching program at the Federal University of Maranhão. For coursework final project, students should design and build small equipment to aid the teaching of chemistry to students with visual impairment. The class was composed of eight students who presented their equipment. One of the students excelled in implementing the activity, producing a single-pan scale and a liquid volume meter, which can be easily used by students with visual impairment. Herein, we demonstrate how the equipment was made and how they can be used, by following an experimental procedure proposed by the student from the Chemistry teaching program.

Keywords: Alternative materials. Chemistry teaching. Inclusive education.

\section{Adeilton Pereira Maciel}

Químico industrial e mestre em Química pela UFPB, doutor em Química pela UFSCar, Especialista em Educação a Distância, SENAC. Atualmente é professor-associado II da Universidade Federal do Maranhão, lotado no Departamento de Química, coordena a área de ensino de Química. Docente permanente 
nos Programas de Pós-Graduação em Energia e Ambiente; Química e RENORBIO.

ap.maciel@ufma.br

\section{Antonio Batista Filho}

Acadêmico do curso de licenciatura em Química na Universidade Federal do Maranhão (UFMA). Curso em fase de conclusão, oitavo período. Profissional autônomo no ramo de transportes rodoviário de materiais.

abatistafilho@hotmail.com

\section{Gilza Maria Piedade Prazeres}

Professora adjunta da Universidade Federal do Maranhão (UFMA). Possui graduação em Química Industrial pela UFMA; mestre e doutora em Ciências Biológicas (Biofísica) pela Universidade Federal do Rio de Janeiro. Coordenou o curso de Química Licenciatura da UFMA. Atualmente atua nas áreas de divulgação científica, ensino de Química e biocombustíveis.

gmp.prazeres@ufma.br 
